\title{
Nematicidal Streptomyces against Meloidogyne incognita by hydrosoluble macromolecules
}

\author{
Qianru Hu \\ Yunnan University \\ Minmin Yang \\ Yunnan University

\section{Tingting Bo} \\ Yunnan University

\section{Yuxin Li} \\ Yunnan University

\section{Caimi Wu} \\ Yunnan University

\section{Minghe Mo \\ Yunnan University} \\ Yajun Liu ( $\nabla$ lyj@ynu.edu.cn ) \\ Yunnan University
}

\section{Research Article}

Keywords: Streptomyces, Meloidogyne incognita, nematicidal activity, hydrosoluble macromolecules

Posted Date: February 17th, 2021

DOI: https://doi.org/10.21203/rs.3.rs-199348/v1

License: (c) (i) This work is licensed under a Creative Commons Attribution 4.0 International License. Read Full License 


\section{Abstract}

Background: Although actinomycetes, which produce antibiotics, have been reported to produce nematicidal metabolites, macromolecules with nematicidal activities have rarely been described.

Results: The culture filtrates of Streptomyces albogriseolus strain DN41 and S. fimicarius strain D153 presented $82.13 \%$ and $86.96 \%$ nematicidal activity against Meloidogyne incognita, respectively, after $12 \mathrm{~h}$. A pot experiment highlighted that these culture filtrates were characterised by significant efficacy. The biocontrol efficiency of strain DN41 reached $61.68 \%$ and that of strain D153 $68.33 \%$ after 30 days at a dose of $100 \mathrm{~mL} \mathrm{pot}^{-1}$. The active metabolites produced by the two strains were hydrosoluble and sensitive to heat, with molecular weights above 8000 Da for DN41 and of 1000-8000 Da for D153. However, these metabolites were negative to protein reaction. A chemical characteristic test indicated that these active metabolites were polar polymers that contained a large amount of sugar and phenolic hydroxyl compounds.

Conclusions: These results revealed S. albogriseolus strain DN41 and S. fimicarius strain D153 as potential agents for the control of root-knot nematodes, as hydrosoluble macromolecules have good compatibility and are convenient for practical application.

\section{Background}

The root-knot nematode Meloidogyneincognita is distributed worldwide and causes increasing loss for vegetable crops annually [1, 2]. Among various control methods, the application of chemical nematicides is the most efficient and most widely used one [3]. However, most chemical agents have been regulated because they are considerably unfriendly to humans and the environment [4]. Therefore, safe and efficient biological control agents have increasingly been used as substitutes for chemical nematicides.

Actinomycete bacteria, especially the major group Streptomyces, produce a large amount of active secondary metabolites that can be used as biological control agents $[5,6]$. For instance, many nematicidal secondary metabolites produced by Streptomyces, such as fervenulin-isolated from Streptomyces sp. CMU-MH021 [7], avermectin-isolated from S. avermitilis G8-17 [8], nemadectin-isolated from S. microflavus neau3 [9], actinomycins-isolated from S. antibioticus M7 [10], milbemycin-isolated from S. bingchenggensis BCJ60 [11], carbazomycins D and F-isolated from Streptomyces sp. CMUJT005 [4], macrocyclic lactones-isolated from S. avermitilis NEAU1069 [12], angumycinones-isolated from Streptomyces sp. P294 [13], fungichromin B-isolated from Streptoverticillium albireticuli HA10002 [14], and SH2-isolated from S. hydrogenans DH16 [15], have been reported. Notably, majority of these metabolites have low molecular weights and are water-insoluble compounds, and hydrosoluble macromolecules with nematicidal activities have rarely been described.

In the present study, two actinomycete strains with high nematicidal activity against Meloidogyne incognita, namely Streptomyces albogriseolus strain DN41 and S. fimicarius strain D153, were isolated from soil samples. The preliminary isolation and structural determination of the active metabolites produced by these strains indicated that these nematicidal metabolites were hydrosoluble, heat-sensitive macromolecules, but not proteins. Furthermore, the active substances in the culture filtrates were characterised and the control effect of the filtrates on root-knot nematodes was assessed.

\section{Results}

\section{Nematicidal activity of culture filtrates and extracts}

The culture filtrates of the two Streptomyces strains displayed significant nematicidal activity against $M$. incognita after $12 \mathrm{~h}, 24 \mathrm{~h}$, and $48 \mathrm{~h}$. The mortality generated by strain DN41 reached $82.13 \%$ and that by strain D153 $86.96 \%$ after $12 \mathrm{~h}$. Notably, the highest effects exceeded $96 \%$ mortality after 48 h. (Fig. 1A) 
After the extraction of the organic solution, the aqueous phase was characterised by the strongest nematicidal activity and the respective mortality generated by strains DN41 and D153 surpassed $98.5 \%$ after $12 \mathrm{~h}$. In contrast, the extracts

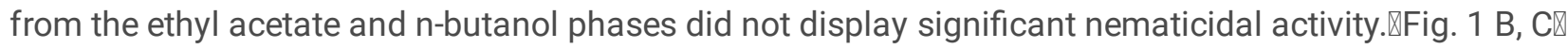

\section{Chemical characteristics of active metabolites}

The active culture filtrates of strains DN41 and D153 were sensitive to heat and their activity were decreased with the increasing of temperature. Nematicidal activity was the highest at $37^{\circ} \mathrm{C}$, then decreased by $66 \%$ for strain DN41 and 50 $\%$ for strain D153 at $47^{\circ} \mathrm{C}$, and was inhibited at $67^{\circ} \mathrm{C}$. (Fig. $2 \mathrm{~A}, \mathrm{~B}$ )

The nematicidal activity of dialysate DN41 reached $98.00 \% 12 \mathrm{~h}$ after dialysis with a molecular weight cut-off at 8000$10000 \mathrm{Da}$, whereas no activity was detected for dialysate D153. In contrast, when performing a dialysis with a molecular weight cut-off at 1000 Da the nematicidal activity of dialysate D153 reached $94.99 \%$ after 12 h. (Fig. 2 C, D)

Notably, enzyme hydrolysis with proteinase-K did not significantly affect the dialysate of either strain. Furthermore, the reactions of ninhydrin biuret and ammonium sulphate precipitation were negative, which indicated that there were no amino acids, peptides, or proteins in the dialysates of both culture filtrates. Fehling's solution reacted with both dialysates and resulted in brick red precipitates, whereas Keller-Kiliani reactions were negative. This implied that the active substances contained reducing sugar but no a-deoxyglucose. Moreover, ferric chloride reactions were negative with the two dialysates, while potassium ferricyanide-ferric chloride tests were positive, which highlights that the dialysates contained aromatic amines and their reductive substances but no phenolics. Additionally, the production of lead acetate precipitates revealed there were tannins. However, the TLC detection of hydrolysed samples indicated there was no gallic acid nor catechinic acid. Likewise, phenolics, lactones, steroids, triterpenoids, and saponins were not detected in the two active dialysates. (Table 1 )

Finally, the organic elemental analysis determined that the molecular formula of the active metabolite produced by strain DN41 was $\left(\mathrm{C}_{34} \mathrm{H}_{75} \mathrm{O}_{63} \mathrm{~N}\right)_{n}$, and that of the active metabolite associated with strain D153 was $\left(\mathrm{C}_{7} \mathrm{H}_{13} \mathrm{O}_{9} \mathrm{~N}\right)_{\mathrm{n}}(\mathrm{Table} 2)$.

\section{Pot experiment}

The culture filtrates of the two strains were significantly more efficient against $M$. incognita than the negative control was after 30 days of treatment. Notably, the inhibition ration in per $1 \mathrm{~g}$ soil of the positive control reached $96.87 \%$, and the highest inhibition ration of the strain DN41 and D153 was of $81.54 \%$ at the dose of $180 \mathrm{~mL} \mathrm{pot}^{-1}$ and the strain D153 was $97.56 \%$ at the dose of $100 \mathrm{~mL} \mathrm{pot}^{-1}$, respectively (Fig. $3 \mathrm{~A}$ ). The inhibition ration in per $1 \mathrm{~g}$ root of the positive control reached $77.83 \%$, and the highest inhibition ration of the strain DN41 was of $66.42 \%$ at the dose of $180 \mathrm{~mL}^{-1}$ and the strain D153 was $77.79 \%$ at the dose of $100 \mathrm{~mL} \mathrm{pot}^{-1}$, respectively(Fig. $3 \mathrm{~B}$ ). The biocontrol efficiency of the positive control reached $68.33 \%$, and the highest biocontrol efficiency of strains DN41 and D153 was of $61.68 \%$ and $68.33 \%$, respectively, at the dose of $100 \mathrm{~mL} \mathrm{pot}^{-1}$ (Fig. 4). Furthermore, the culture filtrates of both strains did not damage the plants, and, after 30 days, promoted greater plant height than the negative control did (Fig. 5).

\section{Discussion}

Natural products produced by actinomycetes, especially Streptomyces spp., are important biological resources to control root-knot nematodes [7]. In recent years, there have been multiple studies on the control of root-knot nematodes through the secondary metabolites produced by Streptomycete [16]. Notably, the culture filtrates of $S$. avermitilis Manp [17] and $S$. hydrogenans DH16 [15] have been reported to cause $89.54 \%$ and $90.00 \%$ mortality against M.incognita, respectively, after $72 \mathrm{~h}$. In our study, S. albogriseolus strain DN41 and S. fimicarius strain D153 were newly reported to have effect on M.incognita. Notably, the mortality generated by the culture filtrates of S. albogriseolus ND41 and S. fimicarius D153 has 
been reported to exceed $82 \%$ after $12 \mathrm{~h}$ and $96 \%$ after $48 \mathrm{~h}$. This highlights that the two strains have a better effect on the control of M. incognita in vitro. In our pot experiment, the treatments with the culture filtrates of strains DN41 and D153 were characterised by a significant biocontrol efficiency, especially at the dose of $100 \mathrm{~mL} \mathrm{pot}^{-1}$, and their effects were close to the positive control avermectin.

The nematicidal metabolites of the two strains of actinomycetes evaluated in the present study both are compounds with a large polarity and are soluble in water but only slightly soluble in organic solvents. Their active substances are sensitive to heat and, hence, are inhibited at high temperatures. Through dialysis, we determined that the molecular weight of the active substance of strain $A$ is above $8000-10000 \mathrm{Da}$, while that of the active substance of strain $B$ is relatively small, namely between 1000 and $8000 \mathrm{Da}$. We first speculated that the active substances were proteins. However, after the addition of Protease-K, the activity of these substances was not affected. Furthermore, the reactions of biuret and ninhydrin, as well as the precipitation of ammonium sulphate, were all negative, which indicates that the active substances of the two strains of Actinomyces were heat-sensitive macromolecular compounds, but not proteins. Notably, these compounds contained a large amount of reducing sugars, but no a-deoxyglucose, lactone ring structure, steroids, nor triterpenes. Additionally, the metabolites did not contain phenolic compounds, but included aromatic amines and reductive substances. Based on the hydrolysis with potassium ferricyanide-ferric chloride reaction and lead acetate precipitation reaction, we inferred that the samples might be tannins, and gallic acid, catechin, and the hydrolysed samples would all be positive to the same chromogenic reaction. However, no gallic acid nor catechin was detected with TLC after hydrolysis. A possible explanation is that the large amount of phenolic hydroxyl in the structure of the active substance induced the positive result of the colour reaction of potassium ferricyanide-ferric chloride. Therefore, the nematicidal compounds may be polymers containing number of phenolic hydroxyl groups and sugars. Based on the elemental analysis, the molecular formula of the active substance of strain DN41 is $\left(\mathrm{C}_{34} \mathrm{H}_{75} \mathrm{O}_{63} \mathrm{~N}\right)_{n}$, and that of the active substance of strain D153 is $\left(\mathrm{C}_{7} \mathrm{H}_{13} \mathrm{O}_{9} \mathrm{~N}\right)_{n}$. Nonetheless, the structures of these macromolecular compounds are complex, and further investigation is required to clarify the bonding between the groups in these compounds.

To date, few hydrosoluble macromolecules with nematicidal activity have been reported. The water-soluble nucleoside antibiotic 1100-50, which was isolated from S. lavendulae SANK 64297, partly inhibited M. hapla J2s after 24 h [18]. Moreover, the actinomycete strain Snea253 produced amino oligosaccharides with a $98.21 \%$ nematicidal activity against M.incognita $24 \mathrm{~h}$ after treatment with $1 \mathrm{~mL}$ of crude extracts [19]. In the present study, we discovered new hydrosoluble macromolecule polymers with a strong nematicidal activity, which contain number of sugars and phenolic hydroxyl compounds.

\section{Conclusions}

In conclusion, in our study, the two strains of $S$. albogriseolus ND41 and S. fimicarius D153 showed significant nematicidal activity against $M$. incognita, and significant biocontrol potentials in pot experiment, expecially at the dose of $100 \mathrm{~mL}^{-1}$.

Moreover, the two strains showed no damage on the plant growth. We discovered new hydrosoluble macromolecule polymers with a strong nematicidal activity, which contain number of sugars and phenolic hydroxyl compounds. As hydrosoluble compounds have good compatibility and are convenient for application, the results of our study provide a baseline for the development of novel nematicides against root-knot nematodes.

\section{Methods}

\section{Preparation of nematodes and actinomycetes}


M. incognita were obtained from infected tomato plants based on Kihika et al. [20]. Root pieces with galls were uprooted and washed with running water to remove the soil. Nematode eggs were selected, under a dissecting microscope, with a 300-mesh sieve in a culture plate containing sterile water, then placed in dark conditions at $27^{\circ} \mathrm{C} \pm 2{ }^{\circ} \mathrm{C}$ for $2-5$ days. Hatched juveniles (J2s) were collected for subsequent nematicidal activity assay and pot experiment.

The actinomycetes $S$. albogriseolus DN41 and S. fimicarius D153 were isolated from soil samples obtained from tomato roots infested with $M$. incognita in Yunnan Province, China. The strains DN41 and D153 were cultured in sterile liquid MB medium at $28^{\circ} \mathrm{C}$ and $180 \mathrm{rpm}$ for 7 days [21]. The cultures were then filtered with a $0.22-\mu \mathrm{m}$ membrane and the filtrates were stored at $4{ }^{\circ} \mathrm{C}$ for subsequent use.

\section{Nematicidal activity assay}

The nematicidal activity of culture filtrates, extracts, and dialysates against $M$. incognita were measured according to the modified method of Park et al. [22]. Freshly hatched J2s were added to a 16-well plate (200 J2s in $20 \mu \mathrm{L})$ and treated with $1 \mathrm{~mL}$ test samples. Sterile water served as control. Every treatment had three replicates and was repeated three times. Plates were placed in an incubator at $25^{\circ} \mathrm{C} \pm 1.0^{\circ} \mathrm{C}$. The number of dead juveniles was counted after 12,24 , and $48 \mathrm{~h}$. Nematodes were considered dead if their bodies were straightened and could not move upon contact with a fine needle, as observed under a microscope. Correction mortality was calculated as follows: Correction mortality $(\%)=\left(D_{t r}-D_{c}\right) /$ $\left(D_{T}-D_{c}\right) \times 100$, where $D_{t r}$ is the death number in the treatment group, $D_{c}$ is the death number under control conditions, and $D_{T}$ is total death number.

\section{Extraction of active metabolites}

The culture filtrates of the two Streptomyces strains were extracted with ethyl acetate firstly and raffinate phase were extracted with n-butanol sequentially. The ethyl acetate, n-butanol, and aqueous phase extracts were dissolved in methanol and diluted to a $5 \%$ methanol aqueous solution. The final concentration of each sample was adjusted to $1 \mathrm{mg}$ $\mathrm{mL}^{-1}$ for the nematicidal activity test.

Culture filtrates $(1 \mathrm{~mL})$ with nematicidal activity were added to $2 \mathrm{~mL}$ centrifugal tubes, then heated $1 \mathrm{~h}$ in a water bath at $37^{\circ} \mathrm{C}, 47^{\circ} \mathrm{C}, 57^{\circ} \mathrm{C}, 67^{\circ} \mathrm{C}, 77^{\circ} \mathrm{C}, 87^{\circ} \mathrm{C}$, and $97^{\circ} \mathrm{C}$, respectively. The nematicidal activity of each sample was tested after heating.

The culture filtrates were eluted with XAD-16 resin (Amberlite, USA) to remove non-polar compounds. Eluates were placed into pretreated dialysis bags (Spectrumlabs, USA) with a molecular weight cut-off at $1000 \mathrm{Da}$ and 8000-10 000 Da, respectively, and dialyzed for 24-48 h. The dialysis buffer was replaced every 3-6 h. The dialysates were freeze-dried. Parts of the dialysates were diluted with deionized water to a concentration of $1 \mathrm{mg} \mathrm{mL}^{-1}$ for the nematicidal activity test.

\section{Determination of chemical characteristics}

Each active dialysate solution $(1 \mathrm{~mL})$ was transferred to a $2-\mathrm{mL}$ centrifugal tube, to which $1 \mu \mathrm{L}$ of $20 \mathrm{mg} \mathrm{mL}^{-1}$ proteinase$\mathrm{K}$ was added for hydrolysis, $2 \mathrm{~h}$ at $37^{\circ} \mathrm{C}$. The respective nematicidal activity of hydrolysates was then tested.

To identify the chemical components and characteristics of active dialysates, the following reactions were conducted according to the methods from Kong [23]: the ninhydrin reaction to identify amino acids, biuret reaction and ammonium sulfate precipitation test to identify peptides and proteins, Fehling's solution and Keller-Kiliani reaction to identify sugar, ferric chloride reaction to identify phenols, potassium ferricyanide-ferric chloride reaction to identify aromatic amine, lead acetate precipitation to identify tannins, hydroxamic acid iron test to identify lactones, thin layer chromatography (TLC) to compare the standards of gallic acid and catechinic acid, and with heated chloroform to identify carcass as well as 
triterpenoids and their glycosides. An organic elemental analyser (Vorio EL, Germany) was used to determinate the molecular formula of active metabolite substances.

\section{Pot experiment}

The pot experiment was performed in a controlled greenhouse environment following the modified method of Hu [24]. Each plastic pot was filled with $150 \mathrm{~g}$ of soil and 3-week-old Zhongza9 tomato seedlings (Jingdian Seeds Company, Yunnan, China) were transplanted. After a week, 500 newly hatched J2s were inoculated per pot. The respective culture filtrates of the two strains were inoculated to pots at different doses, namely $30 \mathrm{~mL} \mathrm{pot}^{-1}, 100 \mathrm{~mL} \mathrm{pot}^{-1}$, and $180 \mathrm{~mL} \mathrm{pot}^{-1}$. The negative control consisted in plants grown in untreated soil, while the positive control corresponded to soil with $2.5 \mathrm{~g}$ $\operatorname{pot}^{-1}$ of $0.5 \%$ avermectin. Each treatment had five replicates and was repeated three times. Pots were cultured in a greenhouse at $27 \pm 2{ }^{\circ} \mathrm{C}$ and watered daily.

After 30 days, plants were uprooted and $10 \mathrm{~g}$ rhizosphere soil samples were collected from each pot. Juveniles were extracted by modified Baermann funnel technique from soil samples, roots with galls were rinsed with sterilized water and cut $5 \mathrm{~g}$ root from each plant and placed in a culture plate containing sterile water. The nematode populations in per $1 \mathrm{~g}$ soil and root were calculated under a dissecting microscope after setting aside for $24 \mathrm{~h}$ at room temperature. The inhibition ration in per $1 \mathrm{~g}$ soil and root, biocontrol efficiency and growth condition of plant were used to measure the biocontrol potentials of two strains.

Inhibition ration was estimated with the following formula: Inhibition ration $(\%)=\left(N P_{t r}-N P_{c}\right) / N P_{c} \times 100 \rrbracket, w h e r e N P_{t r}$ is the nematode populations in per $1 \mathrm{~g}$ soil or root of the treatment group, $\mathrm{NP}_{\mathrm{c}}$ is the nematode populations in per $1 \mathrm{~g}$ soil under control conditions. Biocontrol efficiency was estimated with the following formula: Biocontrol efficiency $(\%)=\left(\mathrm{GI}_{\mathrm{C}}-\right.$ $\mathrm{GI}_{\mathrm{t}}$ ) $/ \mathrm{GI}_{\mathrm{C}} \times 100$, where $\mathrm{GI}_{\mathrm{C}}$ is the gall index under negative control conditions, and $\mathrm{GI}_{\mathrm{t}}$ is the gall index in the treatment group [25]. The gall index was measured according to a ten-point scale [26]. Moreover, the growth condition of plant was measured with plant height $(\mathrm{cm})$, shoot weight $(\mathrm{g})$, and root weight $(\mathrm{g})$.

\section{Statistical analysis}

Data from the experiments were tested using a one-way analysis of variance, and significant differences were analyzed using SPSS software 26.0, the means of the treatments were compared with Duncan's multiple-range test $(p<0.05)$.

\section{Declarations}

\section{Acknowledgments}

We sincerely acknowledge National Natural Science Foundation Program of China and Grant from the Tenthousand Talents Program in Yunnan Province for the financial support to accomplish this research work.

\section{Authors' contributions}

All authors contributed to the study and conducted experiments. Minmin Yang carried out the main experiments and data collection. Tingting Bo, Yuxin Li, Caimi Wu participated in the pot experiment. Qianru Hu analysed data and wrote a manuscript draft. Minghe Mo participated in experimental design. Yajun Liu guided experimental design and revised the manuscript. All authors read and approved the final manuscript.

\section{Funding}

This work was funded by the National Natural Science Foundation Program of China (31860027) and Grant from the Tenthousand Talents Program in Yunnan Province (YNWR-CYJS-2019-042). 
Availability of data and materials

Not applicable.

\section{Ethics approval and consent to participate}

Not applicable.

\section{Consent for publication}

Not applicable.

\section{Competing interests}

The authors declare that they have no competing interests.

\section{Author details}

State Key Laboratory for Conservation and Utilization of Bio-resources, Yunnan University, Kunming 650091, P. R. China

\section{Abbreviations}

ND41: Streptomyces albogriseolus ND41; D153: S. fimicarius D153; J2s: second-stage juveniles.

\section{References}

1. Saxena G. Biocontrol of nematode-borne diseases in vegetable crops. Fruit and vegetable diseases. 2004;1:397-450. doi:10.1007/0-306-48575-3_11.

2. Ruanpanun P, Nimnoi P. Evaluation on the efficiency and persistence of Streptomyces jietaisiensis strain A034 in controlling root knot disease and promoting plant growth in the plant-parasitic n-ematode infested soils. Biological Control. 2020;144:104221. doi:10.1016/j.bio control.2020.104221.

3. Mukhtar T, Arooj M, Ashfaq M. Resistance evaluation and host status of selected green gram germplasm against Meloidogyne incognita. Crop Protection. 2017;92:198-202. doi:10.1016/j.cropro.2016.10.004.

4. Ruanpanun $P$, Dame $Z T$, Laatsch H. 3-Methoxy-2-methyl-carbazole-1, 4-quinone, carbazomycins $D$ and $F$ from Streptomyces sp. CMU-JT005. FEMS Microbiol Lett.2011;322(1):77-81. doi:10.1111/j.1574-6968.2011.02335.x.

5. Law JW, Ser HL, Khan TM. The Potential of Streptomyces as Biocontrol Agents against the Rice Blast Fungus, Magnaporthe oryzae (Pyricularia oryzae). Front Microbiol. 2017;8:3. doi:10.3389/fmicb.2017.00003.

6. Paulus $C$, Rebets $Y$, Tokovenko B. New natural products identified by combined genomics-metabolomics profiling of marine Streptomyces sp. MP131-18. Sci Rep. 2017;7(1):42382. doi:10.1038/srep42382.

7. Ruanpanun P, Laatsch $\mathrm{H}$, Tangchitsomkid N. Nematicidal activity of fervenulin isolated from a nematicidal actinomycete, Streptomyces sp. CMU-MH021, on Meloidogyne incognita. World J Microbiol Biotechnol. 2011;27(6):1373-1380. doi:10.1007/s11274-010-0588-z.

8. Huang J, Chen AL, Zhang H. Gene Replacement for the Generation of Designed Novel Avermectin Derivatives with Enhanced Acaricidal and Nematicidal Activities. Appl Environ Microbiol. 2015;81(16):5326-5334. doi:10.1128/AEM.01025-15.

9. Yang LY, Wang JD, Zhang J. New nemadectin congeners with acaricidal and nematocidal activity from Streptomyces microflavus neau3 Y-3. Bioorg Med Chem Lett. 2013;23(20):5710-5713. doi:10.1016/j.bmcl.2013.08.002. 
10. Sharma, Jasrotia, Ohri. Nematicidal potential of Streptomyces antibioticus strain M7 against Meloidogyne incognita. AMB Express. 2019;9(1):168. doi:10.118 6/s13568-019-0894-2.

11. Li JS, Qi H, Zhang SY. Two new milbemycin derivatives from a genetically engineered strain Streptomyces bingchenggensis. J Asian Nat Prod Res. 2020;1-6. doi:10.1080/10286020.2020.1783656.

12. Wang XJ, Wang M, Wang JD. Isolation and identification of novel macrocyclic lactones from Streptomyces avermitilis NEAU1069 with acaricidal and nematocidal activity. J Agric Food Chem. 2010; 58(5): 2710-2714. doi: 10.1021/jf902496d.

13. Su H, Shao H, Zhang K. Antibacterial metabolites from the Actinomycete Streptomyces sp. P294. J Microbiol. 2016; 54(2): 131-135. doi:10.1007/s12275 -016-5311-9.

14. Zeng Q, Huang H, Zhu J. A new nematicidal compound produced by Streptomyces albogriseolus HA10002. Antonie Van Leeuwenhoek. 2013; 103(5):1107-1111. doi:10.1007/s10482-013-9890-8.

15. Kaur T, Jasrotia S, Ohri P. Evaluation of in vitro and in vivo nematicidal potential of a multifunctional streptomycete, Streptomyces hydrogenans strain DH16 against Meloidogyne incognita. Microbiol Res. 2016;192:247-252. doi: 10.1016/j.micres.2016.07.009.

16. Nimnoi P, Ruanpanun P. Suppression of root-knot nematode and plant growth promotion of chili (Capsicum flutescens L.) using co-inoculation of Streptomyces spp. Biological Control. 2020;145:104244. do $\mathrm{i}: 10.1016 / \mathrm{j}$. biocontrol.2020.104244.

17. Jayakumar J. Bio-efficacy of Streptomyces avermitilis culture filtrates against root knot nematode, Meloidogyne incognita and reniform nematodes, Rotylenchulus reniformis. Karnataka Journal of Agricultural Sciences. 2009; 22(3):567-571.

18. Toshio T, Nobuo H, Mizue I. 1100-50, a Novel Nematocide from Streptomyces lavendulae SANK 64297. The Journal of antibiotics. 2003;56(3):306-309. doi: 10.1002/chin.200335184.

19. Li L, Zhao D, Liu X. Toxicity of Oligosaccharide and Nematicidal-active Substance Produced by Actinomycetes Snea253 to Meloidogyne incognita. Nat Prod Res Dev. 2014;26:117-22+93.

20. Kihika R, Murungi LK, Coyne D. Parasitic nematode Meloidogyne incognita interactions with different Capsicum annum cultivars reveal the chemical constituents modulating root herbivory. Sci Rep. 2017;7(1):2903. doi:10.1038/s41598-017-02379-8.

21. Yu J, Liu Q, Liu Q. Effect of liquid culture requirements on antifungal antibiotic production by Streptomyces rimosus MY02. Bioresour Technol. 2008;99(6):2087-2091. doi:10.1016/j.biortech.2007.03.023.

22. Park EJ, Jang HJ, Park CS. Evaluation of Nematicidal Activity of Streptomyces yatensis KRA-28 against Meloidogyne incognita. J Microbiol Biotechnol. 2020; 30(5):700-7. doi:10.4014/jmb.1908.08038.

23. Kong LY. Natural medicinal chemistry. Beijing: China Medical Science and Technology Press. 2015.

24. Hu Y, Li J, Li J. Biocontrol efficacy of Pseudoxanthomonas japonensis against Meloidogyne incognita and its nematostatic metabolites. FEMS Microbiol Lett, 2019;366(2). doi:10.1093/femsle/fny287.

25. Zou YX, Zhang XF, Zhang JL. Toxicity and Control Efficiency of Different Nematicides to Southern Rootknot Nematodes, Meloidogyne incognita.

26. Start JL. Methods for evaluating plant species for resistance to plant-parasitic nematodes. The Society of Nematologists, Hyattsville, Maryland USA. 1990;16-23.

\section{Tables}

Table 1 Chemical Characteristics of active metabolites 


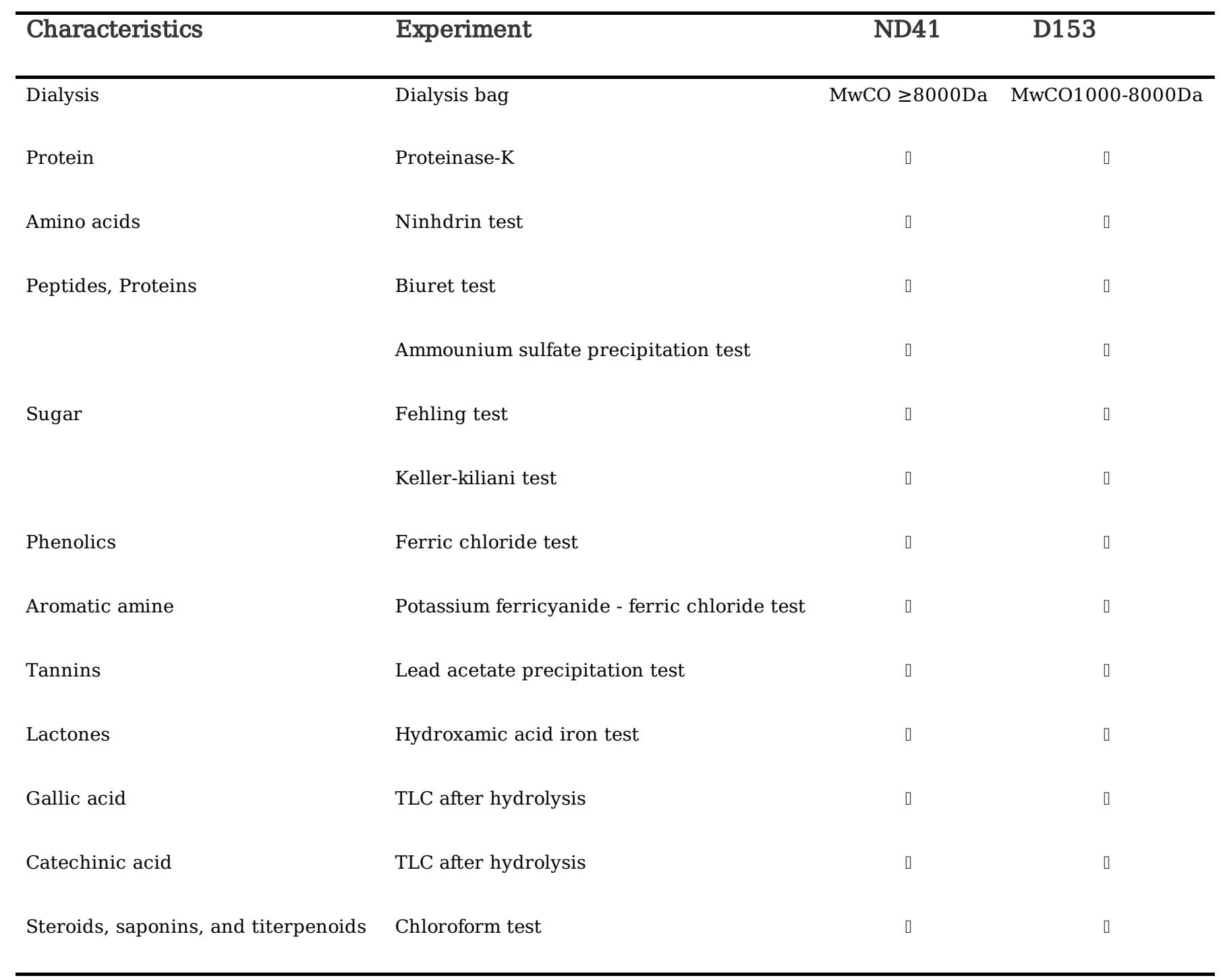

“+”: Positive reaction; “ $\square ”:$ Negative reaction.

Table 2 The elementary analysis of active samples

\begin{tabular}{lllll}
\hline Strain & Molecular formula & $\mathrm{C} / \mathrm{N}$ Ratio & Content (\%) & Peak Area \\
\hline $\mathrm{ND} 41$ & $\left(\mathrm{C}_{34} \mathrm{H}_{75} \mathrm{O}_{63} \mathrm{~N}\right)_{\mathrm{n}}$ & 37.18 & $\mathrm{~N}: 0.957$ & $\mathrm{~N}: 421$ \\
& & & $\mathrm{C}: 35.56$ & $\mathrm{C}: 12526$ \\
& & $\mathrm{H}: 5.106$ & $\mathrm{H}: 7811$ \\
$\mathrm{D} 153$ & $(\mathrm{C} 7 \mathrm{H} 13 \mathrm{O} 9 \mathrm{~N})_{\mathrm{n}}$ & 6.451 & $\mathrm{~N}: 5.168$ & $\mathrm{~N}: 490$ \\
& & & $\mathrm{C}: 33.34$ & $\mathrm{C}: 2301$ \\
& & & $\mathrm{H}: 5.130$ & $\mathrm{H}: 1668$ \\
\hline
\end{tabular}

Figures 

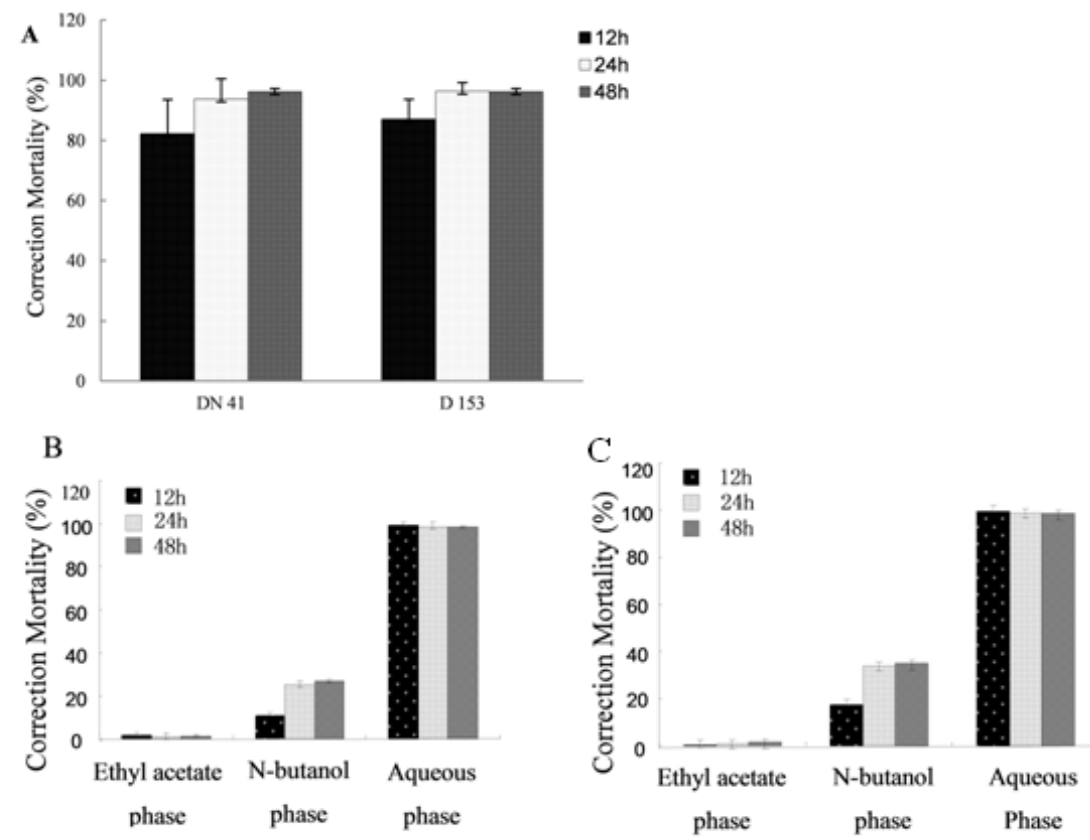

\section{Figure 1}

Nematicidal activity of culture filtrates and extracts of two strains against M. incognita. A. nematicidal activity of culture filtrates, DN41: S. albogriseolus DN41; D153: S. fimicarius D153; B. nematicidal activity of extracts of the strain ND41; C. nematicidal activity of extracts of the strain D153. The experiment was performed with three replicates and data was the average of replicates. The bar means standard deviation. 

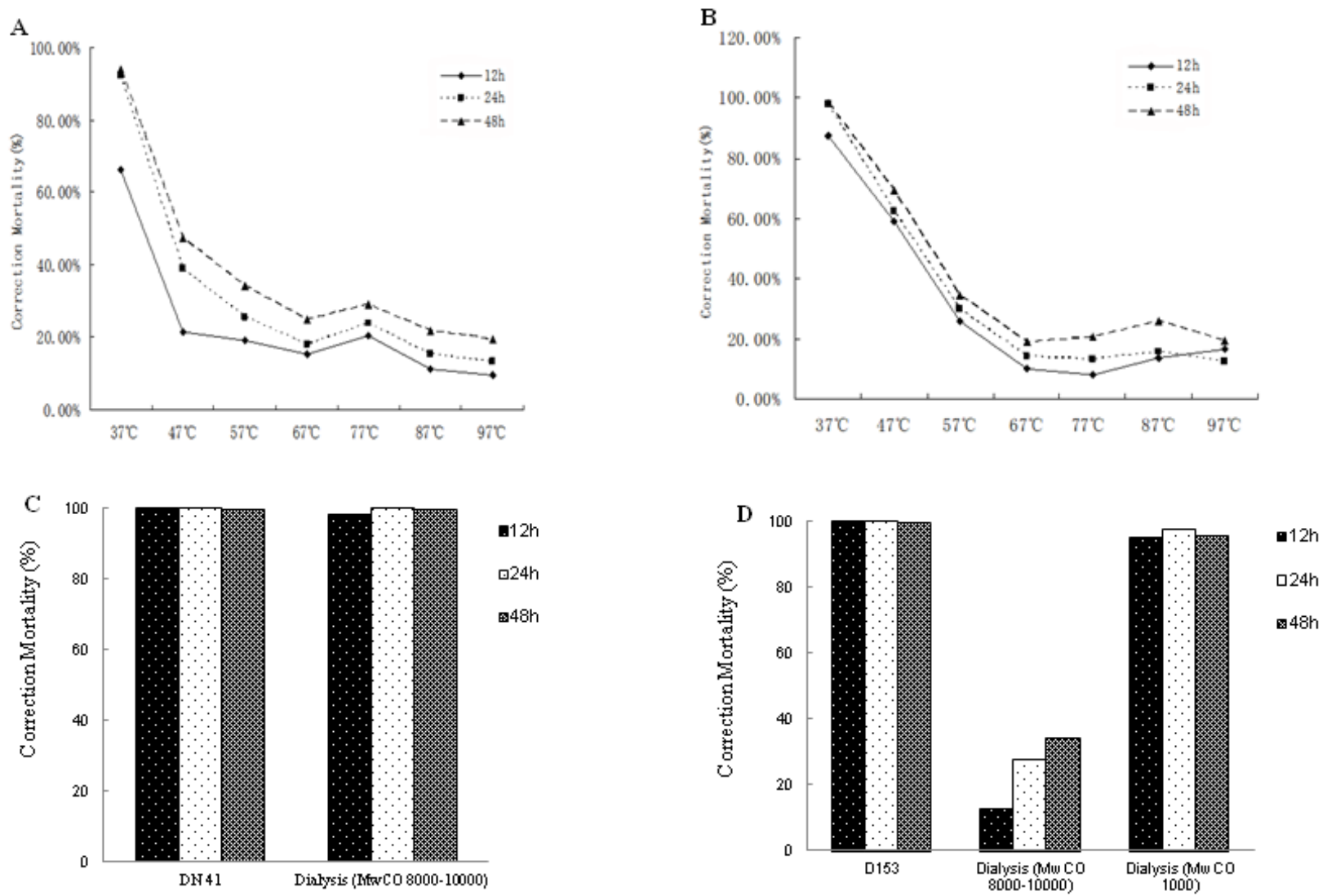

Figure 2

The effect of different temperature and dialysis on the nematicidal activity of two strains against M. incognita. A. response of S. albogriseolus ND41 to temperature; B. response of S. fimicarius D153 to temperature; C. nematicidal activity of dialysate from S. albogriseolus ND41; D. nematicidal activity of dialysate from S. fimicarius D153. 
A

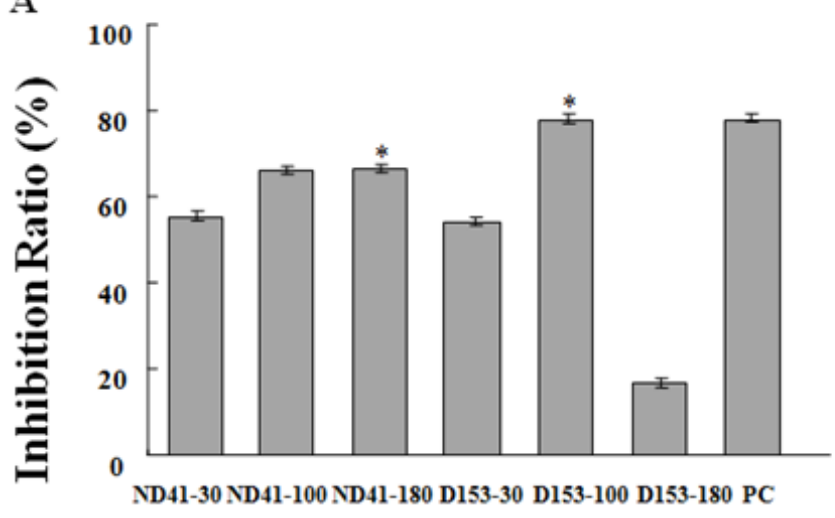

B

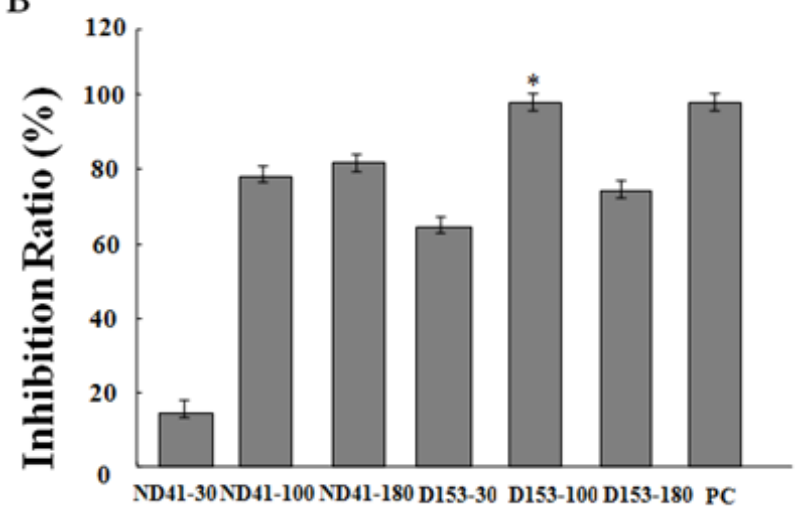

Figure 3

The inhibition ratio of two strains against $\mathrm{M}$. incognita in soil and root at different doses. A. the inhibition ratio against $\mathrm{M}$. incognita in soil.; B. the inhibition ratio against M. incognita in root. ND41-30, ND41-100 and ND41-180 were treated with culture filtrates of S. albogriseolus ND41 at the dose of 30mL pot-1, $100 \mathrm{~mL}$ pot-1 and $180 \mathrm{~mL}$ pot-1. D153-30, D153-100 and D153-180 were treated with culture filtrates of S. fimicarius D153 at the dose of $30 \mathrm{~mL}$ pot-1, $100 \mathrm{~mL}$ pot- 1 and 180 $\mathrm{mL}$ pot-1. PC were treated $2.5 \mathrm{~g}$ pot-1 of $0.5 \%$ avermectin. The experiments were performed with three replicates and data was the average of replicates. The bar means standard deviation. $*$ present the significant difference $(p<0.05)$. 


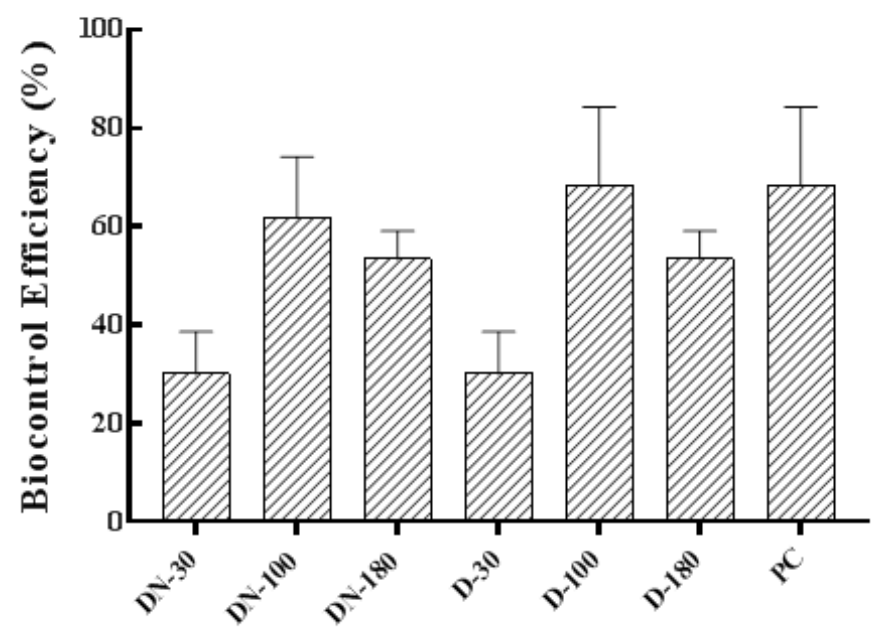

\section{Figure 4}

Biocontrol efficiency of two strains against M. incognita at different doses. ND41-30, ND41-100 and ND41-180 were treated with culture filtrates of S. albogriseolus ND41 at the dose of $30 \mathrm{~mL}$ pot-1, $100 \mathrm{~mL}$ pot-1 and $180 \mathrm{~mL}$ pot-1. D15330, D153-100 and D153-180 were treated with culture filtrates of S. fimicarius D153 at the dose of 30mL pot-1, $100 \mathrm{~mL}$ pot-1 and $180 \mathrm{~mL}$ pot-1. PC were treated $2.5 \mathrm{~g}$ pot- 1 of $0.5 \%$ avermectin. The experiment was performed with five replicates and data was the average of replicates. The bar means standard deviation. 


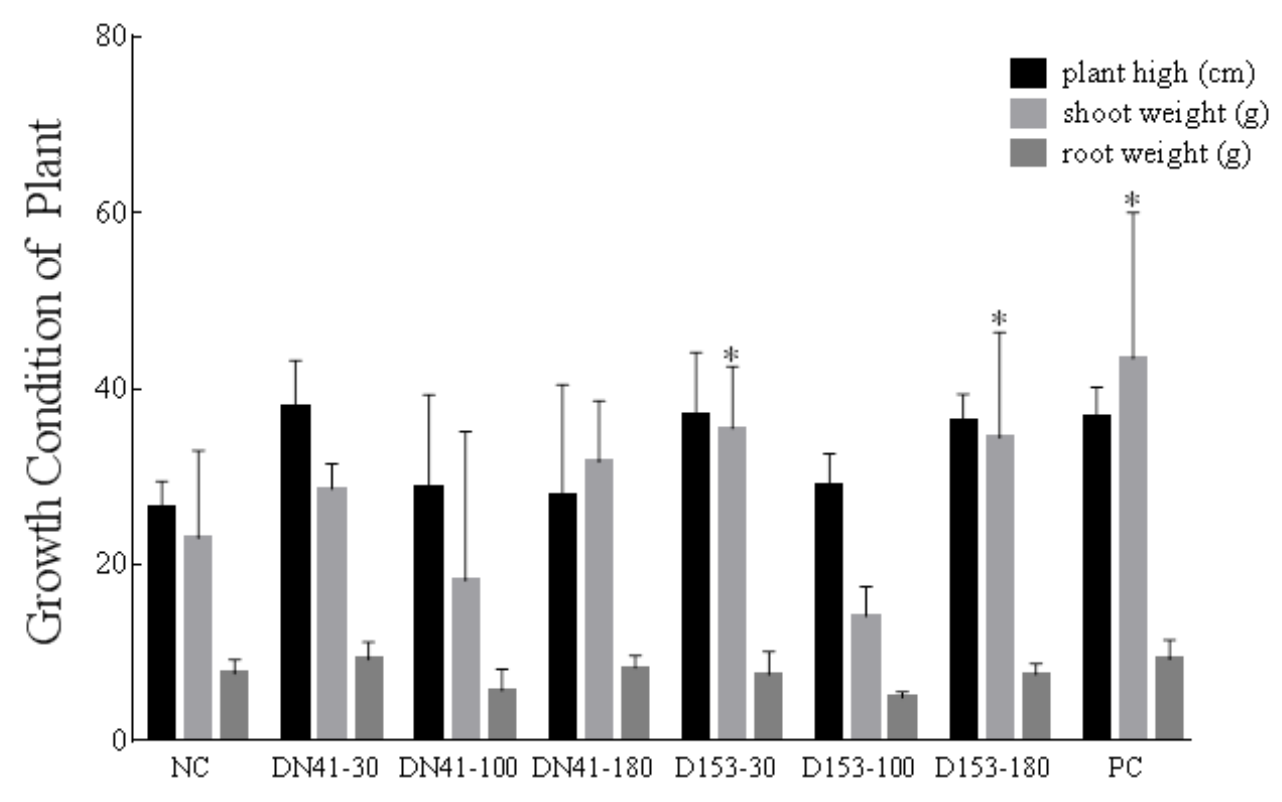

Figure 5

Plant growth treated by two strains at different doses. ND41-30, ND41-100 and ND41-180 were treated with culture filtrates of S. albogriseolus ND41 at the dose of $30 \mathrm{~mL}$ pot-1, $100 \mathrm{~mL}$ pot-1 and $180 \mathrm{~mL}$ pot-1. D153-30, D153-100 and D153-180 were treated with culture filtrates of S. fimicarius D153 at the dose of $30 \mathrm{~mL}$ pot-1, $100 \mathrm{~mL}$ pot-1 and $180 \mathrm{~mL}$ pot-1. PC were treated $2.5 \mathrm{~g}$ pot-1 of $0.5 \%$ avermectin. The experiment was performed with five replicates and data was the average of replicates. The bar means standard deviation. 